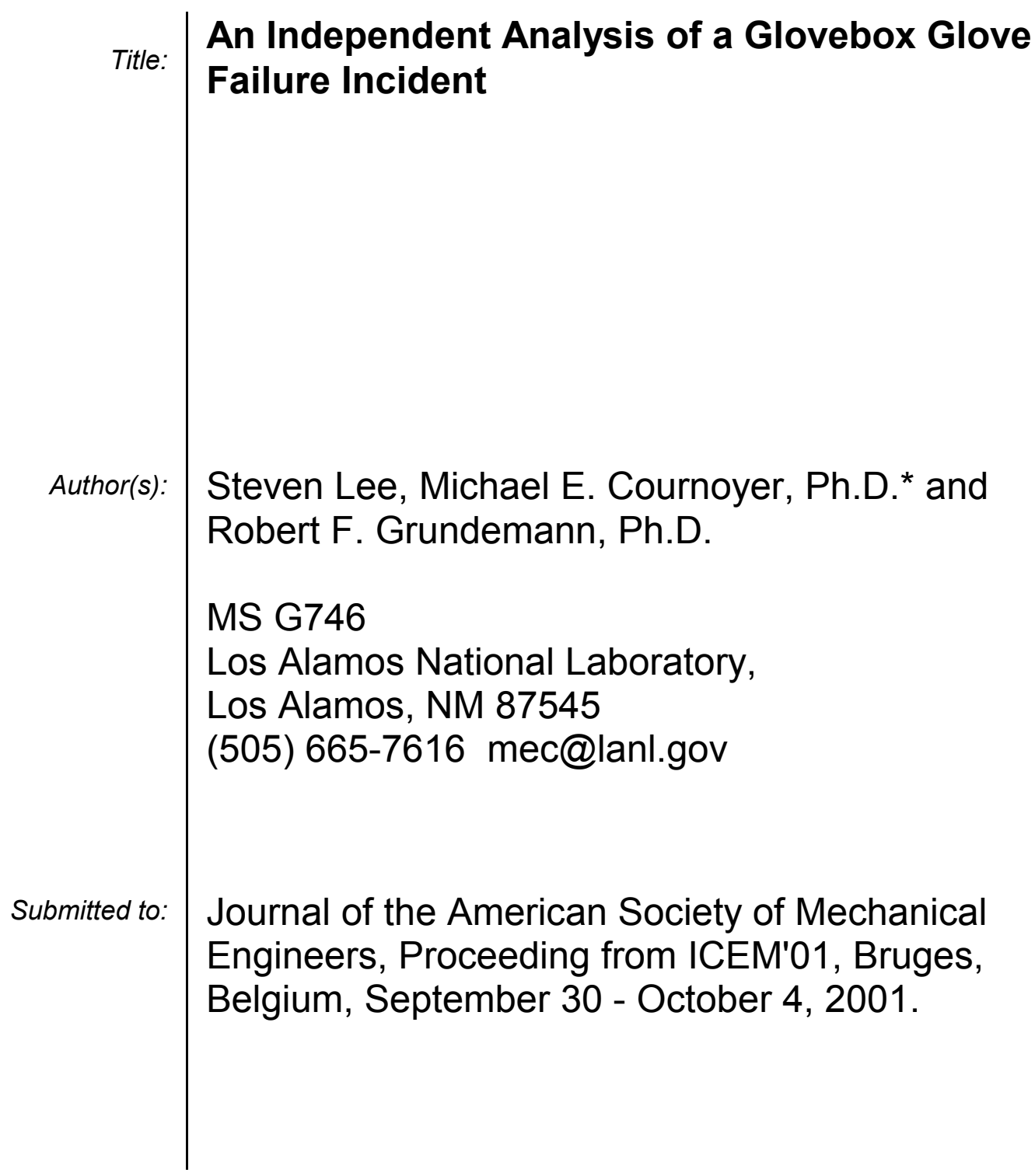




\title{
An Independent Analysis of a Glovebox Glove Failure Incident
}

\author{
Michael E. Cournoyer, Ph.D.* \\ Steven Lee \\ Robert F. Grundemann, Ph.D. \\ Nuclear Material Technology Division \\ Los Alamos National Laboratory, \\ Los Alamos, NM 87545 \\ (505) 665-7616
}

\begin{abstract}
As part of the "Lessons Learned" Program, a recent glovebox glove failure incident is examined to provide feedback and continuous improvement of the Safe Work Practices (SWPs) workcontrol process. While slowly evaporating liquid from solutions in trays on hot plates, a glovebox became pressurized and a glove ruptured resulting in widespread contamination of equipment, work surfaces, and the floor. Based on the post-analysis of the solution and residues of the incident, several contributing causes of the overpressurization were ruled-out, including exposure to strong shock, organic materials, and inorganic species. Evaporation of an ammonium nitrate solution was postulated as the cause of the incident glovebox breach. Since ceramic-top stirring hotplates heat from $150^{\circ} \mathrm{C}$ to $590^{\circ} \mathrm{C}$ and are controlled by a voltage power controller, the temperature to reach rapid decomposition conditions $\left(210^{\circ} \mathrm{C}\right)$ was possible. The risk of these types of incidents is control to acceptable level by replacing voltage power controlled hotplates with temperature controlled ones. In addition, a still pot thermometer is required to prevent the solution from evaporating to dryness. Using a heating device designed such that $210^{\circ} \mathrm{C}$ cannot be reached under any circumstances further minimizes the risk. In summary, a primary objective of the Integrated Safety Management program is to minimize hazards associated with materials whenever possible. Implementing "Lessons Learned" not only maintains SWPs, but also contributes to an organization's scientific and technological excellence. As with all other elements of business, there are costs associated with implementing an effective "Lessons Learned" Program. Using a cost-benefit analysis for another category of reportable occurrences, radiation exposure, it was estimated that over $\$ 50,000$ could be spent on "Lessons Learned" to reduce the likelihood of this type of unusual occurrences and still be cost-effective. While the cost saving may not be immediately apparent, feedback in the form of incident reports provide continuous improvement in day-to-day operations.
\end{abstract}




\section{INTRODUCTION}

Safe Work Practices (SWPs) work-control process is an essential part of the Integrated Safety Management (ISM) at and applies to issues of environment, safety, and health. This five-step process consists of the following: defining the work; identifying and evaluating the hazards; developing and implementing controls; performing work safely; and providing feedback and continuous improvement. One of the five core functions of ISM at the activity level is the last step: providing feedback and continuous improvement. Relative to the organization of material presented here, the objective is to provide a sense of perspective concerning how well ISM works. To this end, a recent glovebox glove failure incident was selected, a postulated cause of the incident glovebox breach was presented, and the controls developed to prevent and mitigate hazards examined. The intent is for the strengths and weaknesses of the ISM approach to become apparent.

Background In nuclear research facilities, analytical chemistry and metallurgical studies on samples of plutonium and nuclear materials are carried out. Programmatic activity include waste minimization, environmental restoration and remediation, nuclear safeguards, high-temperature superconductivity, support for the Rocky Flats site, mixed waste characterization, support for the Waste Isolation Pilot Project, and Special Nuclear Material (SNM) standards development. During one of these activities, involved recovering highly enriched uranium and separating out Resource Conservation and Recover Act (RCRA) materials to facilitate disposal of the mixed waste. RCRA governs how companies within the United States handle hazardous wastes and the facilities that treat, store, or dispose of these wastes. Approximately 100 kilograms of waste was to be processed under the study. Much of the uranium feed material used in the diffusion process was reclaimed or recycled from processed, spent reactor fuel. The chemical processes for purifying recycled uranium leave trace amounts of transuranic elements and fission products, mainly technetium-99 $\left({ }^{99} \mathrm{Tc}\right)$.

Incident [1] Three trays of ${ }^{99} \mathrm{Tc}$ contaminated solutions were being evaporated from neutralized nitric acid solutions placed on hot plates inside two gloveboxes. The solutions were byproducts from recently completed experiments. The intent of this task was to reduce the volume of the solutions by evaporation, dry any solid residues, and then dispose the residues as a potentially mixed waste. During the procedure, an employee in an adjacent room heard a popping noise and looked through a connecting doorway. The lab technician noticed that a glove had come off one of the gloveboxes and observed brownish fumes issuing from the open glove port. The area was immediately evacuated. Shortly after the incident, the distinctive odor of nitrogen oxides (dioxide, trioxide, tetraoxide) was detected. Emergency response personnel were contacted, and the wing was evacuated. Power to the gloveboxes was not disconnected, and the evaporation process continued for several more hours until the correct breakers were located and opened. Subsequently, responders found that a glovebox glove had blown off. Radiological control technicians later measured general-area contamination levels ranging from 60,000 to more than $1,000,000$ beta disintegrations per minute $(\mathrm{dpm}) / 100 \mathrm{~cm}^{2}$. The primary source of this contamination was ${ }^{99} \mathrm{Tc}$. No personnel were exposed during this event and facility contamination was limited to two rooms. This incident was treated with the severity of a Type B Accident, of which there have been 26 reported, since 1995 (When the Office of Oversight, DOE, first started tracking these types of accidents) [2]. 


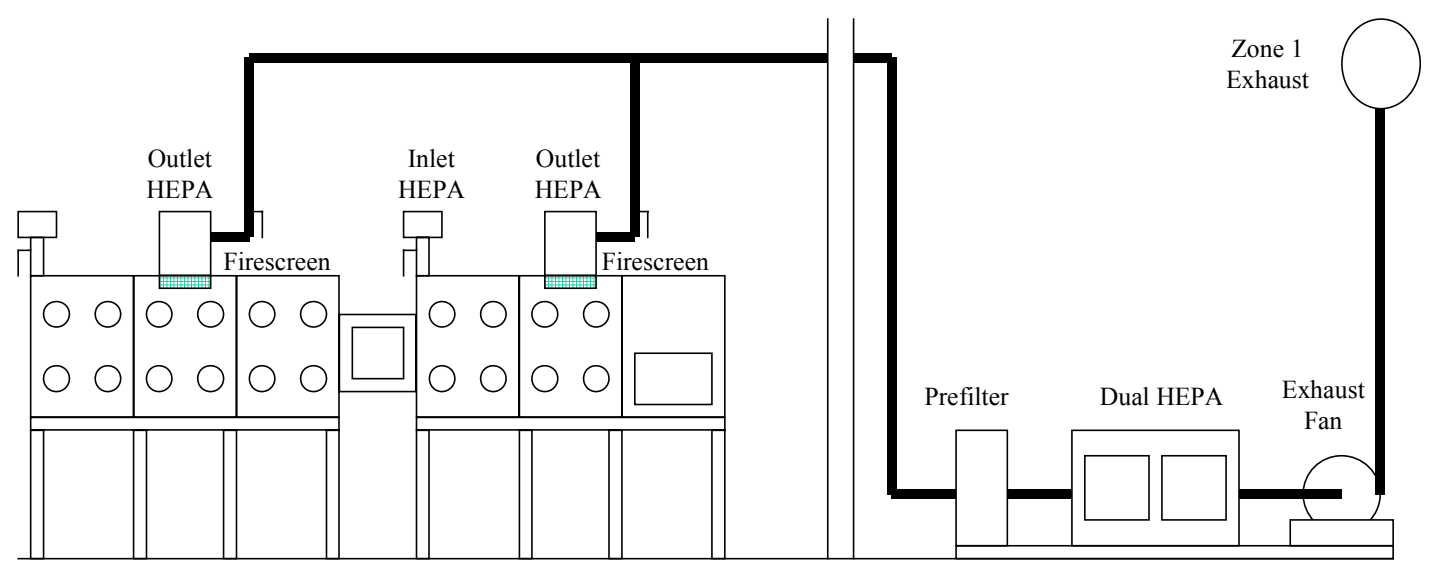

Figure 1. Schematic of GB HVAC Room 4064

Analysis of Solution and Residues [3\} Key components of the glovebox system are shown in Figure 1. Samples of the evaporation materials were collected from the glovebox. The samples included liquid from the last 2-Liter bottle of solution and solids from the trays, fire screens, glovebox floor, and large beakers. Analysis showed the liquid contained high levels of ammonium nitrate, parts per million (ppm) quantities of organic compounds, hydrogen peroxide, nitrite, sulfate, many trace metals including copper, nickel, zinc, ${ }^{99} \mathrm{Tc}$ in the form of pertechnetate $\left(\mathrm{TcO}_{4-}\right)$ and ppm amounts of uranium. The $\mathrm{pH}$ of the solution was between 8 and 9 . Two differential thermal analyses (DTAs) were conducted. In the first test, only the liquid sample of the solution prior to evaporation was heated. No exotherms were observed. Only endotherms from evaporating the water from the sample were found. In the second test, the sample liquid was absorbed on a zeolite ceramic support. After an endotherm was observed for water removal, the remaining dry salts exhibited an exothermic event with a magnitude of approximately $20^{\circ} \mathrm{C}$ at about $310^{\circ} \mathrm{C}$. The analysis of the liquid also showed the solution contained some RCRA metals. Two of these metals were present in quantities above regulatory limits: chromium at $28 \mathrm{ppm}$ versus the limit of $5 \mathrm{ppm}$ and selenium at $6 \mathrm{ppm}$ versus the limit of $1 \mathrm{ppm}$. The materials on the two fire screens had molar ratios of nitrate to ammonium ion of 1.11 and 1.03 , respectively. This ratio is smaller than the 1.19 ratio in the solution. The fire screen materials contained the same elements found in all other samples. All samples in the trays and on the glovebox floors had enrichment of nitrate ion over the ammonium ion ranging from 1.36 to greater than $1.48 .{ }^{99} \mathrm{Tc}$ was depleted of ammonium ions relative to other metals in these samples. Samples in the beakers were slightly lower in ${ }^{99} \mathrm{Tc}$ and showed enrichment in nitrate relative to ammonium ions.

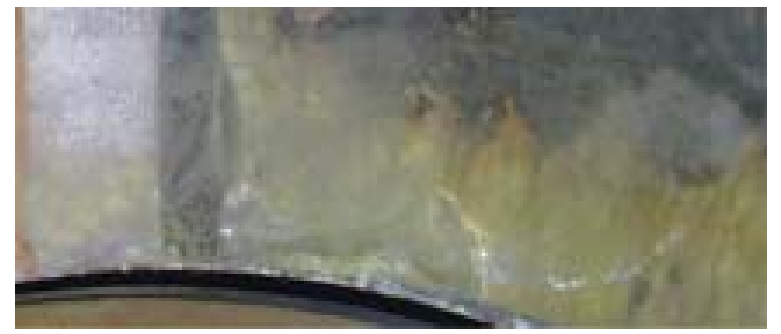

Figure 2. Crack Above Glove Port of the Glovebox.

Analysis of Glovebox and Glove [3] An approximate six-inch crack was found in the glass above the right, upper-middle glove port of the glovebox, as shown in Figure 2. This was the port next to the blown-off glove. No other damage was found in the glovebox. Inspection of the fire screens in both boxes revealed that the screens were almost completely clogged with solid residues, as shown in Figure 3. 


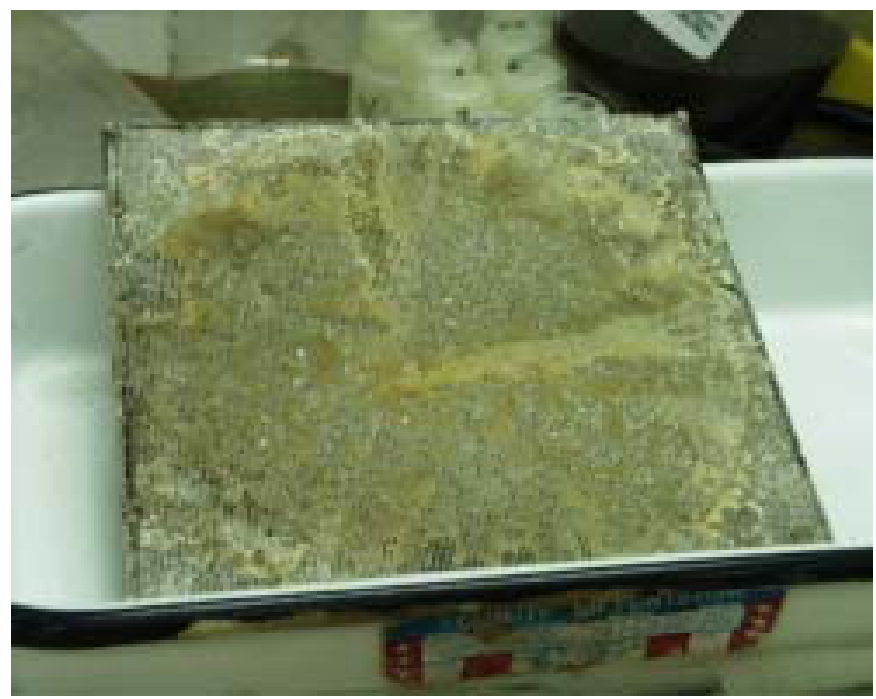

Figure 3. Fire Screens Clogged with Solid Residues.

Inspection of the High Efficiency Particulate Air (HEPA) filters showed that the filter media in the upstream side of the filters was significantly deformed and thus allowed a significant flow of air through the filter without having to pass through the filter media, as shown in Figure 4.

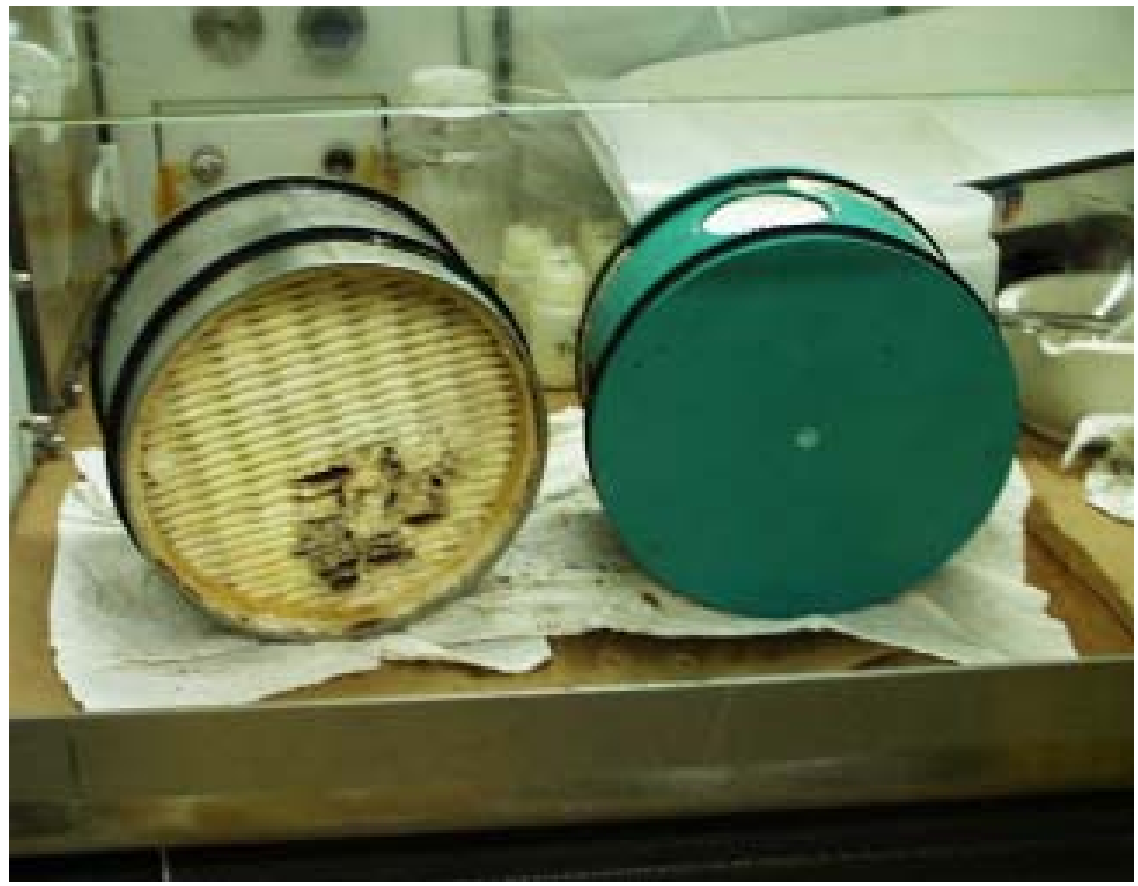

Figure 4. Upstream Side of Deformed High Efficiency Particulate Air (HEPA) Filter.

The hypalon glove was manufactured by North in 1995 and had a tensile of 13 megapascals minimum. The glove was in two distinct pieces. A complete circumference rupture was located in the arm section about $13 \mathrm{~cm}$ below the cuff where the glove was attached to the glove port. The second section had a rupture running from the arm section down to the forearm section. Dark discoloration of the white glove was noted around the inside of the cuff. The section of glove that 
remained in the port was white, while the section below was discolored. Manual pulling of the glove showed that it still had elasticity and was not brittle or crumbling.

\section{AMMONIUM NITRATE}

Ammonium nitrate is a compound containing nitrogen, hydrogen, and oxygen $\left(\mathrm{NH}_{4} \mathrm{NO}_{3}\right)$ and is commercially produced by reacting nitric acid with ammonia, evaporating the resultant solution of ammonium nitrate to make a concentrated ammonium nitrate melt, which is then spray granulated in a prilling tower or palletized or flaked by some other means. In solid or molten form or in solution, ammonium nitrate is a stable compound and generally is difficult to explode. Ammonium nitrate must be exposed to strong shock or to high temperature (over $210^{\circ} \mathrm{C}$ ) under confinement for this to occur.

As it relates to the above-discussed incident, ammonium nitrate is capable of undergoing detonation with about half the blast effect of explosives, if heated under confinement that permits high-pressure build-up. Hot aqueous solutions of the nitrate of above $50 \%$ concentration may decompose explosively under adiabatic conditions and under conditions of confinement (small, or no vents) [4]. The decomposition, fire and explosion hazards of ammonium nitrate have been adequately reviewed [5-8]. Depending on the conditions, presence of free ammonia in ammonium nitrate may either stabilize, or tend to destabilize, the salt [9]. When one considers the safety of the process of neutralization of nitric acid with ammonia, the effects of temperature, pressure, and concentrations of ammonium nitrate and of nitric acid upon decomposition rate have been studied [10]. The thermal decomposition rate increases sharply with the free nitric acid, especially at low temperatures.

The effect of various impurities and additives on the thermal stability of ammonium nitrate has also been widely studied $[5,6,11]$. Impure ammonium nitrate now constitutes more than $95 \%$ of all civil explosives used in the United States of America. A few incidents involving explosive decomposition of aqueous solutions of the salt during evaporation have been recorded [12,13]. Contaminants may increase the explosion hazard of ammonium nitrate. Organic materials generally will make ammonium nitrate explosions more energetic. Ammonium nitrate may be sensitized by certain inorganic contaminants, including chlorides and some metals, such as chromium, copper, cobalt, and nickel. In addition, as ammonium nitrate solution becomes more acidic, its stability decrease, and it may be more likely to explode [14]. Low density areas such as bubbles, in molten ammonium nitrate or solutions, also may increase the possibility of an explosion and enhance the propagation of an explosion. Ammonium nitrate by itself does not burn, but in contact with other combustible materials, it increases the fire hazard. It can support and intensify a fire even in the absence of air. Fires involving ammonium nitrate can release toxic nitrogen oxides and ammonia. A fire involving ammonium nitrate in an enclosed space could lead to an explosion. Closed containers of ammonium nitrate solution may rupture violently when heated.

\section{DISCUSSION}

According to the Incident Investigative Report, the direct cause of the incident was the overpressurization of a glovebox due to a rapid but non-explosive decomposition of chemical compounds while subjected to heat [3]. Whether an explosion occurred or not is not particularly important. Nevertheless, enough stored energy was released to crack the glass in the glovebox and tear a glovebox glove. The molar ratios of nitrate to ammonium on the two fire screens indicate the solid residue was ammonium nitrate, with a slight excess of the nitrate. Splattering or aerosol transport occurred during the incident, since the fire screen materials contained the same elements found in all other samples. Ammonium nitrate solution is capable of this type of energy 
release, if the proper explosive conditions, when it is exposed to strong shock or to high temperature under confinement, exist. While the former condition did not exist the latter condition was possible. Typical ceramic-top stirring hotplates heat from $150^{\circ} \mathrm{C}$ to $590^{\circ} \mathrm{C}$. With $\mathrm{pH}$ of samples being slightly basic, this would indicate that an excess nitric acid was not present, which would have account for a sharp increase in the decomposition rate. While $0.2 \%$ or more organic material would have increased the explosion hazard ammonium nitrate, less than $100 \mathrm{ppm}$ was reported. It has been reported that metal salts, especially chromium(VI) salts are most effective in promoting the decomposition of ammonium nitrate. However, the concentrations of chromium and other salts found in the post-incident analysis were insignificant. Last, as the trays of solution probably evaporated to dryness, it is likely that gas bubbles were generated.

The DTA analysis of the liquid showed that dry, solid nitrate compounds would decompose. The $310^{\circ} \mathrm{C}$ initiation of the exothermic reaction noted for the sampled solution indicate that this solution is more stable than solid ammonium nitrate that has a reported decomposition temperature of $210^{\circ} \mathrm{C}$. Although not determined, DTA analysis on the more concentrated solution that would have existed in the trays at the time of the incident would have been desired.

Based on the above discussions, the following is presented as a probable cause of the incident:

- The solution being concentrated contained significant amounts of ammonium nitrate.

- The solution was allowed to evaporate to dryness, thereby allowing the temperature to rise above $210^{\circ} \mathrm{C}$.

- This situation also presents the possibility of forming low-density areas such as bubbles, in molten ammonium nitrate or solutions, which may increase the possibility of an explosion and enhance the propagation of an explosion.

- At this point the solution rapidly decomposed into gases that included various colored oxides of nitrogen.

The most significant lessons learned from this incident are the following:

1. Adjusting the temperature of the hotplate (cost $\sim \$ 150)$ such that the temperature of evaporation is never above $80^{\circ} \mathrm{C}$ does not guarantee that higher temperatures will be reached once the solution has evaporated to dryness.

2. Temperature controlled hotplates that maintain the set temperature either at the plate surface by an internal Type $\mathrm{K}$ thermocouple sensor, or in the solution is required over a voltage power controller.

3. An improvement on Lessons Learned 2 is using a heating device (Infrared Lamp) designed such that $210^{\circ} \mathrm{C}$ cannot be reached under any circumstances.

4. A still pot thermometer is also required to prevent the solution from evaporating to dryness and generating low density areas such as bubbles

Costs associated with buying the required equipment are small. For example, hotplates cost around $\$ 150$ dollars, while infrared lamps cost only about $\$ 50$ more.

The main goal of an effective "Lessons Learned" program is to decrease the risk associated with this type of unusual occurrence to an acceptable level. From a business viewpoint, the acceptable level may be achieved when the costs of decreasing a given risk further are greater than the costs realized from the spread of radioactive contamination. Since the magnitude of a risk involves both the probability and severity of the associated harm, a "Lessons Learned" program can be reasonably based on reducing either the severity or the probability, or both. Using values from cost-based occurrences of this magnitude [15], the cost of cleanup, downtime, and time spent investigating accidents, etc. is estimated at over one million dollars, as shown in Table I. For another category of reportable occurrences, radiation exposure, cost-benefit analysis for radiation exposure have been used to make decisions, i.e. "Lessons Learned," to ensure that the most cost-effect dose reduction measures are implemented [16]. Cost-benefit analyses typically apply monetary equivalents of $\$ 1,000$ to $\$ 10,000$ per person-rem with the recommended nominal value being $\$ 2,000$ per person-rem. Optimization analyses are performed whenever the 
cost of these measures exceeds $\$ 50,000$ or the collective dose to be avoided is greater that 5 person-rem. Since this particular incident involved the spread of radioactive contamination of more than $1,000,000$ disintegrations per minute $(\mathrm{dpm}) / 100 \mathrm{~cm}^{2}$, over $\$ 50,000$ could be spent on "Lessons Learned" to reduce the likelihood of this type of unusual occurrences and still be costeffective.

Table I. Criteria that trigger an Unusual Occurrence.

\begin{tabular}{|l|l|}
\hline Groups of Unusual Occurrences & \multicolumn{1}{|c|}{ Criteria } \\
\hline $\begin{array}{l}\text { Facility Condition: Loss of control of } \\
\text { Radioactive Material or Spread of } \\
\text { Radioactive Contamination* }\end{array}$ & $>100,000(\mathrm{dpm}) / 100 \mathrm{~cm}^{2}$ \\
\hline $\begin{array}{l}\text { Personnel Radiological Protection: } \\
\text { Radiation Exposure }\end{array}$ & $>5 \mathrm{rem}^{* *}$ \\
\hline $\begin{array}{l}\text { Value Base Reporting: Cost-Based } \\
\text { Occurrences }\end{array}$ & $\geq \$ 1,000,000$ \\
\hline
\end{tabular}

${ }^{*} \mathrm{dpm}=$ disintegrations per minute

** rem $=$ Roentgen equivalent man

\section{CONCLUSIONS}

The following conclusions were reached. In the absence of impurities it is difficult, but not impossible, to cause ammonium nitrate to detonate. If allowed to evaporate to dryness, hotplates controlled by a voltage power controller have the potential to reach temperatures well above $210^{\circ} \mathrm{C}$. Temperature controlled hotplates that maintain the set temperature well below $210^{\circ} \mathrm{C}$ combined with a still pot thermometer are necessary in order for the rapid decomposition of ammonium nitrate solution to be prevented. This recommendation of using temperaturecontrolled hotplates for heat sensitive processes has been implemented throughout the nuclear research facility.

In summary, a primary objective of the ISM program is to minimize hazards associated with materials whenever possible. Implementing step 5 of the 5 -step process not only maintains SWPs, but also contributes to an organization's scientific and technological excellence. As with all other elements of business, there are costs associated with implementing an effective "Lessons Learned" Program. While the cost saving may not be immediately apparent, feedback in the form of incident reports provide continuous improvement in day-to-day operations.

\section{ACKNOWLEDGEMENTS}

The authors would like to acknowledge the Department of Energy and LANL's Nuclear Weapons -Materials \& Manufacturing Program Office, for support of this work. 


\section{REFERENCES}

1. Occurrence Reporting and Processing System (ORPS) Report ALO-LA-LANL-CMR-19990020 and references therein.

2. http://tis.eh.doe.gov/oversight/reports/accidents/.

3. Unpublished results.

4. Kolaczkowski, A. et al., Chem. Abs., 1982, 97, 78074.

5. B.T. Federoff, Encyclopedia of Explosives and Related Compounds, Vol. I, Piccatinny Arsenal, Dover1960, p. 35.

6. Chemistry and Technology of Explosives, T. Urbanski, Pergamon Press, Oxford, 1965, Vol. 2, p. 460.

7. Popper, H., Chem. Eng., 1962, 70, p. 91.

8. Sykes, W. G. et al., Chem. Eng. Progr., 1963, 59 (1), p. 66.

9. Kohczkowski, A. et al., J. Chem. Technol. Biotechnol., 1981, 31, pp. 327-332.

10. Rubtsov, Yu. I. et al., Chem. Abs ., 1987, 106, 158775.

11. Mellor, J.W., Comprehensive Treatise on Inorganic and Theoretical Chemistry, London, Longmans Green, 1964, Vol. 8, Suppl. 1, p. 543.

12. Case Histories of Accidents in the Chemical Industry, Washington, MCA Guide, 1972, p. 308.

13. Croysdale, L. G. et al., Chem. Eng. Progr., 1965, 61 (1), p. 76.

14. "Explosion Hazard from Ammonium Nitrate", EPA 550-F-97-002d, December 1997.

15. http://www.directives.doe.gov/pdfs/doe/doetext/neword/232/m2321-1a.pdf

16. LIR402-700-01, Occupational Radiation Protection Requirements, Los Alamos National Laboratory (2001). 